\title{
Therapeutic effects of virtual reality video gaming on functional mobility, balance, and gait speed in individuals with tropical spastic paraparesis: A randomized crossover clinical trial
}

\author{
Erika Pedreira da Fonseca ${ }^{[1],[2],}$ Katia Nunes Sá ${ }^{[2]}$, Rebeca Freitas Reis Nunes ${ }^{[2],}$ \\ Camille Rosa de Jesus Souza ${ }^{[2]}$, Mayra Castro de Matos Sousa ${ }^{[2]}$ and Elen Beatriz Pinto ${ }^{[2]}$
}

[1]. Universidade Católica do Salvador, Departamento de Fisioterapia, Salvador, BA, Brasil.

[2]. Escola Bahiana de Medicina e Saúde Pública, Departamento de Pós-Graduação, Salvador, BA, Brasil.

\begin{abstract}
Introduction: Individuals with human T-cell lymphotropic virus 1-associated myelopathy/tropical spastic paraparesis (HAM/TSP) experience sensorimotor alterations, which can affect functional performance. Virtual reality (VR) videogaming is a therapeutic option, though there is scarce evidence for its use in this population. We aimed to investigate the therapeutic effects of a VR video game on functional mobility, balance, and gait speed in individuals with HAM/TSP. Methods: We conducted a blinded, crossover clinical trial comprising 29 individuals with HAM/TSP and randomized them into two groups: (1) early therapy: rehabilitative protocol started immediately after the initial evaluation and (2) late therapy: rehabilitative protocol started 10 weeks later. We assessed all participants for balance using the Berg Balance Scale (BBS) scores, functional mobility using the Timed Up and Go (TUG) test, and gait speed using video camera and CvMob software. Differences were considered significant if $p<0.05$. Results: The early therapy group individuals presented with higher BBS scores $(p=0.415)$, less TUG times $(p=0.290)$, and greater gait speed $(p=0.296)$ than the late therapy group individuals. Conclusions: VR videogaming is a useful option for rehabilitative therapy in individuals with HAM/TSP; it positively affects balance, functional mobility, and gait speed.
\end{abstract}

Keywords: Gait. Tropical spastic paraparesis. Mobility limitation. Postural balance. Virtual reality.

\section{INTRODUCTION}

Human T-cell lymphotropic virus 1 (HTLV-1)-associated myelopathy/tropical spastic paraparesis (HAM/TSP) is a neurological disorder characterized by demyelination of the central nervous system, predominantly the spinal cord $^{1-5}$. Initial signs of HAM/TSP include a reduction in muscular strength, lower-limb spasticity, and sphincter disorders ${ }^{6}$. This disease results in functional motor, sensory, and autonomic dysfunctions that lead to changes in gait, impaired balance, and loss of functional mobility, thereby increasing the risk of falling ${ }^{1-5}$. Additionally, these physiological alterations may be influenced by fatigue arising from depressive

\footnotetext{
Corresponding author: Erika Pedreira da Fonseca.

e-mail: erikapedreira@gmail.com

(i) https://orcid.org/0000-0002-5572-0553

Received 7 October 2020

Accepted 17 December 2020
}

symptoms as well as diminished social interactions, sense of wellbeing, and physical fitness ${ }^{7,8}$.

HTLV-1 infects an estimated 20 million people worldwide. In Brazil, this infection is endemic with the highest incidence reported in Salvador ${ }^{9}$, the capital of the northeastern state of Bahia. Secondary to HTLV-1 infection ${ }^{10}, 3-5 \%$ of affected individuals develop HAM/TSP, with a higher prevalence in women aged $\geq 40$ years ${ }^{6,9}$. Nevertheless, HTLV-1 remains a neglected disease, and rehabilitation in HAM/TSP is crucial to promote functional improvement in affected individuals $s^{4,11,12}$.

Among the different rehabilitative strategies, studies have demonstrated virtual reality (VR) videogaming as a promising therapeutic option for motor and cognitive rehabilitation in patients with neurological impairments ${ }^{13,14}$, including demyelinating diseases such as HAM/TSP ${ }^{4,15,16}$ and multiple sclerosis ${ }^{16}$. However, evidence regarding the impact of VR in HAM/TSP rehabilitation 
remains unclear. The present study aimed to investigate the effects of rehabilitation via VR videogaming on functional mobility, balance, and gait speed in HAM/TSP patients, considering the importance of these factors in fall prevention.

\section{METHODS}

The present randomized crossover clinical trial (ClinicalTrials. gov: NCT02877030) involved patients aged 18-64 years with independent gait, whose conditions were diagnosed as HAM/ TSP according to the criteria of the World Health Organization ${ }^{17}$. We excluded patients who were pregnant; presented with other neurological conditions, psychiatric disorders, rheumatic or orthopedic diseases; had previously undergone lower-limb amputation; or had difficulty in understanding the instruments used for the evaluation. This trial was part of a larger study approved by the local institutional review board (CAAE 49634815.2.0000.5628). All patients provided written informed consent.

In accordance with the CONSORT (http://www.consortstatement.org/) guidelines, a third party randomized the patients into two groups, late treatment (LT) group and early treatment (ET) group, using the online Random software (https://www.random.org/). Blinded and previously trained investigators evaluated the patients 10 and 20 weeks after the initial assessment, with a 1 -week washout period after group crossover ${ }^{18}$. For analysis, data from the LT group at the second assessment time point were used as controls for ET group, while ET data were used as controls for LT following the final assessment. Patients were asked to maintain their usual activities, including rehabilitation, throughout the evaluation time points.

Patients were evaluated for balance and functional mobility using the Berg Balance Scale (BBS) scores ${ }^{19}$ and the Timed Up and Go test (TUG) ${ }^{20-22}$, respectively. Habitual gait velocity was filmed using a GoPro HERO 3.0 ${ }^{\circledR}$ camera and analyzed with CvMob software ${ }^{23,24}$. In addition, patients answered a demographic questionnaire and provided a history of falls in the last 3 months, defined as "inadvertent fall to the ground or a lower level, excluding intentional changes in position using furniture, walls, or other objects as support" 25 .

The ET group began the sensorimotor exercise protocol immediately after the initial assessment, whereas the LT group, considered as a control group for ET during this initial phase, initiated the protocol only at the beginning of the second 10-week study period. After this time point, the ET group received no therapeutic intervention, constituting the control phase. The ET and LT groups performed sensorimotor exercise sessions lasting $20 \mathrm{~min}$, twice a week for 10 consecutive weeks: ET from weeks 1 to 10 , and LT from weeks 10 to 20, following the 1-week washout period (Figure 1). We connected a VR videogame to a Nintendo Wii ${ }^{\circledR}$ console, in which arrows were randomly cast toward the player from above. Players were asked to move in the direction of the arrows to induce movements that displaced their body's center of pressure using the Nintendo Wii ${ }^{\circledR}$ platform. Initially, arrows appeared at 3-s intervals, with a progressive increase in the appearance of arrows over the rehabilitation treatment period, demanding greater weightshift from the participants. Patients who reported fatigue during a session were allowed to rest; resting periods were not deducted from the overall duration of $20 \mathrm{~min}$ per session.

Statistical analysis was performed using SPSS Statistics for Windows, version 17 (SPSS Inc., Chicago, IL, USA). The demographic and functional characteristics of participants were described with qualitative variables expressed using absolute and

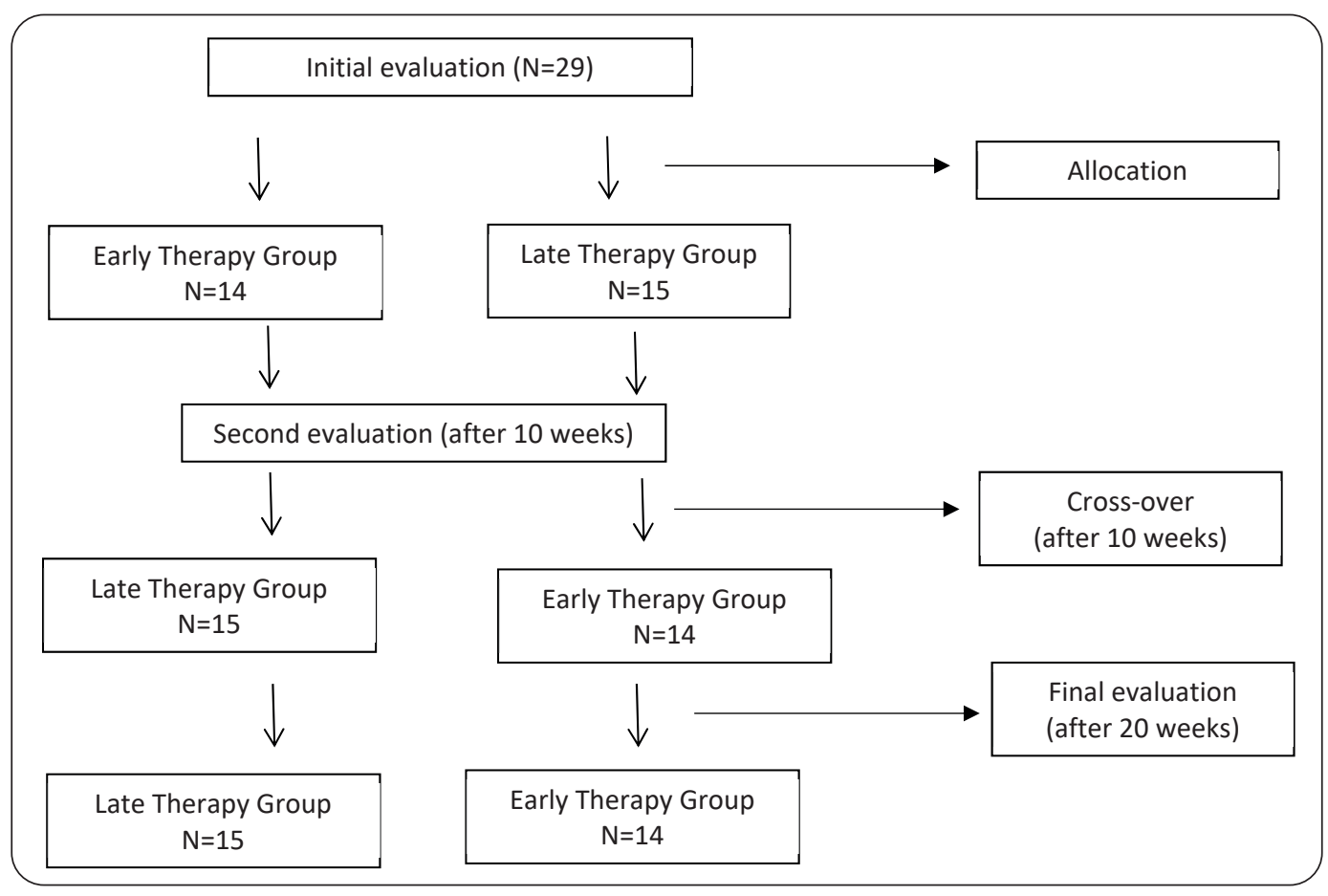

FIGURE 1: Flowchart of the study design in accordance with the CONSORT guidelines. 
relative frequencies. The Shapiro-Wilk test was used to determine the distribution of these variables. The normally distributed variables were described as means and standard deviations, while skewed variables were described as medians and quartiles. We used Student's t and Fisher's exact tests to compare the demographic and functional characteristics. The treatment effect between groups and confidence intervals were assessed using Cohen's d, with values compared with the reference data previously published by Rosenthal et al. (1996) ${ }^{26}$. To evaluate differences in functional mobility, balance, and gait speed between the control and therapy phases of ET and LT groups, repeated-measures ANOVA testing was applied. A $p<0.05$ was considered significant.

The necessary sample size of 12 participants in each group was estimated using the online tool provided by the Laboratory of Epidemiology and Statistics of the University of São Paulo (LEE-USP; http://www.lee.dante.br/), considering a study power of $80 \%$ and $5 \%$ alpha level, standard deviation (SD) of 3, and a 3-s difference detection limit between TUG values ${ }^{4}$. Moreover, $20 \%$ more participants were included in each group, considering possible losses.

\section{RESULTS}

We enrolled 29 patients with HAM/TSP, with therapeutic intervention and evaluations performed between April and December 2017 (Figure 1). Table 1 lists the demographic and functional characteristics of these patients. The analysis revealed no significant differences between ET and LT groups.

Our results indicate that the ET group demonstrated improvement in functional mobility and gait speed, but not balancing ability, which continued at the final evaluation point (i.e., after crossover); however, these differences were not significant. Conversely, we observed the worsening of functional mobility and gait speed in the LT group, despite interventions, over the 6-month period between initial and final evaluations (Figures 2A,B,C).
Comparisons between ET and LT interventions and control phases revealed a medium to large effect in functional mobility during the control phase. Patients in the LT group exhibited worse mean functional mobility scores than those in the ET group (Table 2).

\section{DISCUSSION}

Our results indicate a medium to large effect with regard to functional mobility, as assessed using TUG in the ET group. Studies have demonstrated that rehabilitation involving VR video games gradually provides greater freedom of movement to patients, who reportedly feel safer owing to less fear of falling and can interact physically with ease with their surroundings ${ }^{15,27-32}$. In addition, studies have reported that rehabilitative treatment for sensorimotor impairment contributed to increased adaptive plasticity ${ }^{33}$ and that repetitive practice was positively associated with motor learning ${ }^{34,13}$.

Differences between performance and motor learning have already been described, and some factors, including repetition and motivation, favor knowledge retention and the development of motor memory ${ }^{35}$. Moreover, VR treatment protocols vary greatly among studies ${ }^{30}$. In rehabilitation programs involving patients with multiple sclerosis, the total number of sessions was 10-36 $6^{15,16}$, scheduled 1-3 times a week ${ }^{15,27}$, each lasting from 20-60 $\mathrm{min}^{27,32}$. A literature review identified only one clinical trial involving HAM/TSP patients, employing 30-min VR rehabilitation sessions scheduled three times a week over 8 weeks ${ }^{1}$.

Studies indicate that impaired balance in individuals with myelopathy results from reduced muscle strength ${ }^{35-39}$ and spasticity in the lower limbs ${ }^{2,35,36}$. In addition, sensory changes and associated brain injuries can further compromise postura ${ }^{38-43}$ and motor ${ }^{44}$ control, respectively. Notably, these sensory changes have been primarily associated with altered signal conduction through the ascending pathways in the thoracic spinal region, leading to reduced functional ability ${ }^{43}$. Memory consolidation and consequent motor learning are closely linked to motor and somatosensory information ${ }^{45}$.

TABLE 1: Demographic and functional characteristics of patients $(N=29)$ with HAM/TSP.

\begin{tabular}{|c|c|c|c|c|}
\hline Variables & $\begin{array}{l}\text { Total } \\
(\mathrm{N}=29)\end{array}$ & $\begin{array}{l}\text { Early therapy } \\
\qquad(n=14)\end{array}$ & $\begin{array}{l}\text { Late therapy } \\
\qquad(n=15)\end{array}$ & $p$ value \\
\hline Age in years $(\text { mean } \pm S D)^{a}$ & $51.02 \pm 9.83$ & $46.89 \pm 11.43$ & $52.27 \pm 7.95$ & 0.23 \\
\hline Sex: Female $n(\%)^{b}$ & $16(55 \%)$ & $9(66.7 \%)$ & $7(45.5 \%)$ & 0.40 \\
\hline Use of walking aid, $n(\%)^{b}$ & $15(50 \%)$ & $8(55.6 \%)$ & $7(45.5 \%)$ & 1.00 \\
\hline \multicolumn{5}{|l|}{ History of falls, $\mathrm{n}(\%)^{\mathrm{b}}$} \\
\hline None & $4(15 \%)$ & $3(22.2 \%)$ & $1(9.1 \%)$ & 0.38 \\
\hline One & $4(15 \%)$ & $0(0.0 \%)$ & $4(27.3 \%)$ & 0.38 \\
\hline Two & $2(5 \%)$ & $1(11.1 \%)$ & $0(0.0 \%)$ & 0.38 \\
\hline Three or more & $19(65.0 \%)$ & $10(66.7 \%)$ & $10(63.6 \%)$ & 0.38 \\
\hline Berg Balance Scale score $(\text { mean } \pm S D)^{a}$ & $45.24 \pm 9.96$ & $41.56 \pm 7.93$ & $44.18 \pm 6.41$ & 0.42 \\
\hline Timed Up and Go - seconds (mean \pm SD) ${ }^{a}$ & $17.44 \pm 11.29$ & $22.19 \pm 12.72$ & $18.13 \pm 6.87$ & 0.37 \\
\hline $\begin{array}{l}\text { Gait speed - } \\
\text { meters/seconds (mean } \pm \text { SD) }\end{array}$ & $0.21 \pm 0.9$ & $0.22 \pm 0.09$ & $0.22 \pm 0.09$ & 0.89 \\
\hline
\end{tabular}

SD: standard deviation. ${ }^{a}$ t-test; ${ }^{b}$ Fisher's exact test. 
TABLE 2: Estimation of the size effect in the early therapy and late therapy groups: intervention versus control phases.

\begin{tabular}{lcc}
\hline Variable & Intervention phase & Control phase \\
\hline Balance $(\triangle \mathrm{BBS})$ & $0.192(-0.691-1.075)$ & $0.341(-0.547-1.228)$ \\
Functional mobility $(\Delta \mathrm{TUG})$ & $0.404(-0.948-3.052)$ & $0.553(-0.345-1.45)$ \\
Gait speed change & $0.039(-0.842-0.92)$ & $0.018(-0.863-0.899)$ \\
\hline
\end{tabular}

${ }^{*}$ Cohen's d.

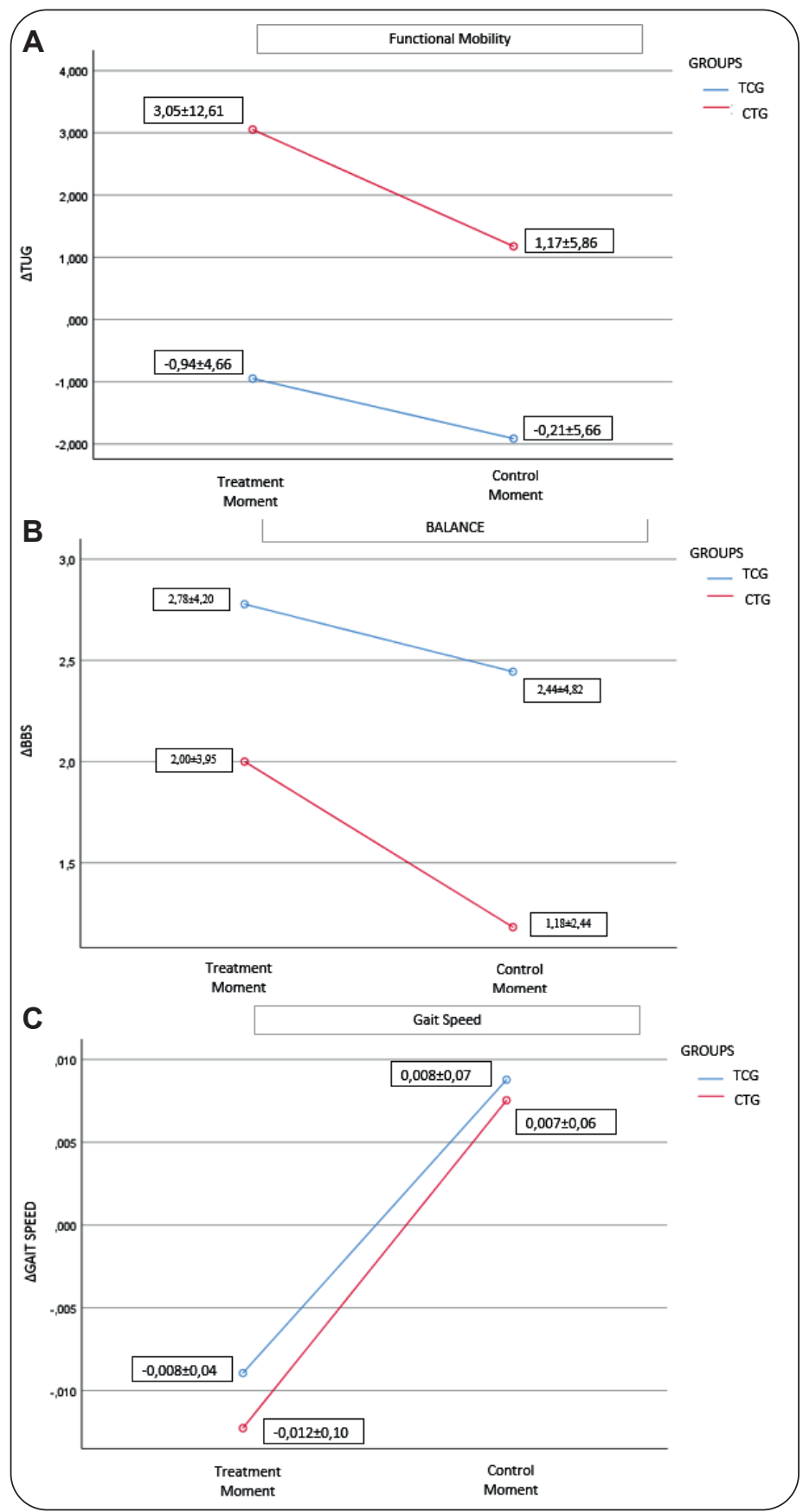

FIGURE 2: (A). Comparison of mean values of functional mobility from $\Delta T T^{*}{ }^{*}$ of human T-cell lymphotropic virus 1-associated myelopathy/tropical spastic paraparesis (HAM/TSP) between $\mathrm{ET}^{* *}$ and $\mathrm{LT}^{* * *}$ at treatment and control times $(p=0.290)$. (B). Comparison of mean values of $\triangle B B S^{* * * *}$ balance of HAM/TSP between ET and LT at treatment and control times $(p=0.415)$. (C). Comparison of mean values of speed of HAM/TSP between ET and LT at treatment and control times $(p=0.296)$. ${ }^{*} \mathrm{TUG}=$ Timed up and Go; ${ }^{* *} \mathrm{ET}=$ Early treatment;

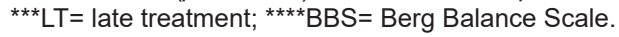

The lower gait speed and inferior TUG performance seen in the LT group could be explained by the natural progression of myelopathy ${ }^{46}$, which leads to impairment in gait and mobility, eventually necessitating the use of walking aids ${ }^{3,6,47}$. Studies have linked functional mobility to several factors, including walking ability, weight transfer, balance, and muscle strength ${ }^{21}$, all of which are impaired in individuals with HAM/TSP 2,37 . Mobility presents as one of the greatest challenges for patients with HAM/ TSP progression ${ }^{36}$, and over $70 \%$ of the affected women report reduced mobility and locomotion ${ }^{3}$. Gait speed was compromised in HAM/TSP patients, despite the use of walking aid devices ${ }^{6}$.

Our results contribute to the body of knowledge surrounding the therapeutic effects of VR video games in the rehabilitation of patients with HAM/TSP. This study has its limitations. The most notable limitation is the small sample size, which is unfortunately common in studies involving this type of myelopathy. Moreover, considering disease progression and the possibility of loss to follow-up, it would be advisable to employ a longer washout time. It would also be interesting to account for the possibility of fatigue in affected individuals when planning session duration times; investigating pain levels could lend further insight.

The size effect of VR videogaming on functional mobility was medium to large exclusively in the HAM/TSP group that underwent rehabilitation therapy earlier in our study.

\section{ACKNOWLEDGMENTS}

We are grateful to the students who contributed to the data collection and the patients, who voluntarily participated in the research.

\section{FINANCIAL SUPPORT}

The work did not have any type of financial support for its accomplishment.

\section{AUTHORS' CONTRIBUTION}

EPF, KNS, RFRN, CRJS, MCMS, EBP: Conception and design of the study, Acquisition of data; Analysis and interpretation of data, Drafting the article, Final approval of the version to be submitted.

\section{CONFLICT OF INTEREST}

The authors declare that there is no conflict of interest.

\section{REFERENCES}

1. Coutinho IJ, Galvão-Castro B, Lima B, Eiter CCD, Grassi MFR. Impact of HTLV-associated myelopathy/T tropical spastic paraparesis (HAM/ TSP) on activities of daily living (ADL) in HTLV-1 infected patients. Acta Fisiátrica. 2011;18(1):6-10. 
2. Champs APS, Passos VMA, Barreto SM, Vaz LS, Ribas JGR. Mielopatia associada ao HTLV-1: análise clínico epidemiológica em uma série de casos de 10 anos. Rev Soc Bras Med Trop. 2010;43(6)668-72.

3. Dias GAS, Yoshikawa GT, Koyama RVL, Fujihara S, Martins LCS, Medeiros R, et al. Neurological manifestations in individuals with HTLV-1-associated myelopathy/tropical spastic paraparesis in the Amazon. Spinal Cord. 2015;1(4):154-7.

4. Arnault VACO, Macêdo M, Pinto EB, Baptista AF, Castro-Filho BG, Sá KN. Virtual Reality Therapy in the treatment of HAM/TSP individuals: randomized clinical trial. Rev Pesq Fisio. 2014;4(2):99-106.

5. Moreno-Carvalho OA, Santos JI, Di Credico G. Evidence of preferential female prevalence of HTLV-I associated tropical spastic paraparesis in Bahia-Brazil. Arq. Neuro-Psiquiatr. 1992;50(2):183-8.

6. Martin F, Fedina A, Youshya S, Taylor GP. A 15 years prospective longitudinal study of disease progression in patients with HTLV-1 associated myelopathy in the UK. J Neurol Neurosurg Psychiatry. 2010;81(12):1336-40.

7. Schwartz CE, Coulthard-Morris L, Zengi Q. Psychosocial Correlates of Fatigue in Multiple Sclerosis. Arch Phys Med Rehabil. 1996;77(2):165-70.

8. Colosimo C, Millefiorini E, Grasso MG, Vinci F, Fiorelli M, Koudriavtseva T, et al. Fatigue in MS is associated with specific clinical features. Acta Neurol Scand. 1995;92(5): 353-5.

9. Gallo RC, Willems L, Tagaya Y. Time to Go Back to the Original Name Frontiers in Microbiology. Front Microbiol. 2017;8:1800.

10. Gessain A, Cassar O. Epidemiological aspects and world distribution of HTLV-1 infection. Front Microbiol. 2012;3:1-23.

11. Sá KN, Macêdo MC, Andrade RP, Mendes SD, Martins JV, Baptista AF. Physiotherapy for human T-lymphotropic virus 1-associated myelopathy: review of the literature and future perspectives. J Multidiscip Healthc. 2015;8:117-25.

12. Neto IF, Mendonça RP, Nascimento CA, Mendes SM, Sá KN. Fortalecimento muscular em pacientes com HTLV-1 e sua influência no desempenho funcional: um estudo piloto [A pilot study: muscle strengthening in patients with HTLV-1 and its influence on functional performance]. Rev Pesq Fisio. 2012;2(2):143-55. Portuguese.

13. Holden MK. Virtual environments for motor rehabilitation: review. Cyberpsychol Behav. 2005;3(3):187-211.

14. Adamovich SV, Fluet GG, Tunik E, Merians AS. Sensorimotor training in virtual reality: a review. NeuroRehabilitation. 2009;25(1):29-49.

15. Lozano-Quilis JÁ, Gil-Gómez H, Gil-Gómez JÁ, Albiol-Pérez S, Palacios-Navarro G, Fardoun HM, et al. Virtual rehabilitation for multiple sclerosis using Kinect-based system: randomized controlled trial. JMIR Serious Games. 2014;2(2):1-8.

16. Eftekharsadat B, Babaei-Ghazani A, Mohammadzadeh M, Talebi M, Eslamian F, Azari E. Effect of virtual reality-based balance training in multiple sclerosis. Neurol Res. 2015;37(6):539-44.

17. World Health Organization (WHO). Human T lymphotropic vírus type, HTLV-1. Wkly Epidemiol Rec. 1988;64:382-383.

18. Borges JDP, Baptista AF, Santana N, Souza I, Kruschewsky RA, Galvão-Castro B, et al. Pilates exercises improve low back pain and quality of life in patients with HTLV-1 virus: a randomized crossover clinical trial. J Bodyw Mov Ther. 2014;18(1):68-74.

19. Miayamoto ST, Junior IL, Berg KO, Ramos LR, Natouri J. Brazilian version of the Berg balance scale. Braz J Med Biol Res. 2004;37(9):1411-21.

20. Podsiadlo D, Richardson S. The Timed "Up \& Go": A Test of Basic Functional Mobilitv for Frail Elderlv Persons. J Am Geriatr Soc. 1991;39(2):142-8.
21. Sebastião E, Sandroff BM, Learmonth YC, Motl RW. Validity of The Timed Up and Go as A Measure of Functional Mobility in Persons with Multiple Sclerosis. 2015; Arch Phys Med Rehabil. 2016;97(7):1072-7.

22. Fonseca EP, Sá KN, Nunes RFR, Ribeiro Junior AC, Lira SFB, Pinto EB. Balance, functional mobility, and fall occurrence in patients with human T-cell lymphotropic virus type-1-associated myelopathy/tropical spastic paraparesis: a cross-sectional study. Rev Soc Bras Med Trop. 2018;51(2):1-6.

23. Pena N, Credidio BC, Corrêa LPNRMS, França LGS, Cunha MV, de Souza MC, et al. Instrumento livre para medidas de movimento. Rev Bras Ensino Fís. 2013;35(3):3505.

24. Quixadá AP, Onodera AN, Pena N, Miranda JGV, Sá KN. Validity and reliability of free software for bidimentional gait analysis. Rev Pesq Fisio. 2017;7(4):548-57.

25. Global report on falls prevention in older age. WHO Library Cataloguingin-Publication Data ISBN 9789241563536 (NLM classification: WA 288) World Health Organization 2007.

26. Rosenthal JA. Qualitative Descriptors of Strength of Association and Effect Size. Journal of Social Service Research. 1996;21(4):37-59.

27. Gutièrrez RO, del Rio FG, la Cuerda RC, Alguacil-Diego IM, Diego A, González RA. A telerehabilitation program by virtual reality-video games improves balance and postural control in multiple sclerosis patients. NeuroRehabilitation. 2013;33(4):545-54.

28. Nilsagard YE, Forsberg AS, von Koch L. Balance execise for person with multiple sclerosis using Wii games: a randomised, controlled multi-centre study. Mult Scler. 2012;19(2):209-16.

29. Massetti T, Trevizan IL, Arab C, Favero FM, Ribeiro-Papa DC, Monteiro CBM. Virtual reality in multiple sclerosis - A systematic review. Mult Scler Relat Disord. 2016;8:107-12.

30. Baram Y, Miller A. Virtual reality cues for improvement of gait in patients with multiple sclerosis. Neurology. 2006;66(2):178-81.

31. Efterkharsadat B, Babaei A, Mohammadzadeh M, Talebi M, Eslamian F, Ezari E. Effect of virtual reality-based balance training in multiple sclerosis. Neurol Res. 2015;37(6):539-44.

32. Brichetto G, Spallarossa P, de Carvalho MLL, Battaglia MA. The effect of Nintendo Wii on balance in people with multiple sclerosis: a pilot randomizes control study. Mult Scler. 2013;19(9):1219-21.

33. Giotakos O, Tsirgogianni K, Tarnanas I. A virtual reality exposure therapy (VRET) scenario for the reduction of fear of falling and balance rehabilitation training of elder adults with hip fracture history. Conference: Virtual Rehabilitation 2007.

34. Levin MF, Weiss PL, Keshner EA. Emergence of virtual reality as a tool for upper limb rehabilitation: incorporation of motor control and motor learning principles. Phys Ther. 2015;95(3):415-25.

35. Shmuelof L, Krakauer JW, Mazzoni P. How is a motor skill learned? Change and invariance at the levels of task success and trajectory control. J Neurphysiol. 2012;108(2):578-94.

36. Kantak SS, Winstein CJ. Learning-performance distinction and memory processes for motor skills: A focused review and perspective. Behav Brain Res. 2012;228(1):219-31.

37. Cartier L, Araya F, Castillo JL, Ruiz F, Gormaz A, Tajima K. Progessive espastic paraparesis associated with human T-cell leucemia vírus type I (HTLV-I). Intern Med. 1992;31(11):1257-61.

38. Caiafa RC, Orsini M, Felicio LR, Puccionii-Shhler M. Muscular weakness represents the main limiting fator of walk, functional independence and quality of life of myelopathy patients associated to HTLV-1. Arq. Neuro-Psiquiatr. 2016;74(4):280-6. 
39. Facchinetti LD, Araújo AQ, Chequer GL, de Azevedo MF, de Oliveira RVC, Lima MA. Falls in patients with HTLV-I-associated myelopathy/ tropical spastic paraparesis (HAM/TSP). Spinal Cord. 2013;51(3):222-5.

40. Caskey MF, Morgan DJ, Porto AF, Giozza SP, Muniz AL, Orge GO, et al. Clinical manifestations associated with HTLV type I infection: a cross-sectional study. AIDS Res Hum Retroviruses. 2007;23(3):365-71.

41. Castillo JL, Cea JG, Verdugo RJ, Cartier L. Sensory dysfunction in HTLV-I-associated myelopathy/tropical spastic paraparesis. Eur Neurol. 1999;42(1):17-22.

42. Leite ACC, Silva MTT, Alamy AH, Afonso CRA, Lima MAD, AndradaSerpa MJ, et al. Peripheral neuropathy in HTLV-I infected individuals without tropical spastic paraparesis/HTLV-I-associated myelopathy. J Neurol. 2004;251(7):877-81.

43. Facchinetti LD, Araújo AQ, Silva MTT, Leite ACC, Azevedo MF, Chequer GL, et al. Home-based exercise program in TSP/HAM individuals: a feasibility and effectiveness study. Arq. Neuro-Psiquiatr. 2017;75(4):221-7.

44. Moritoyo H, Arimura K, Arimura Y, Tokimura Y, Rosales R, Osame M. Study of lower limb somatosensory evoked potentials in 96 cases of HTLV-I-associated myelopathy/tropical spastic paraparesis. J Neurol Sci. 1996;138(1-2):78-81.

45. Araujo AQC, Silva MTT. The HTLV-1 neurological complex. Lancet Neurol. 2006;5(12):1068-76.

46. Cuppone AV, Semprini M, Konczak J. Consolidation of human somatosensory memory during motor learning. Behav Brain Res. 2018;347:184-92.

47. Vasconcelos BHB, Souza GS, Barroso TGCP, Silveira LCL, Sousa $\mathrm{RCM}$, Callegari B, et al. Barefoot plantar pressure indicates progressive neurological damage in patients with human T-cell lymphotropic vírus type 1 infection. Plos One. 2016;11(3):1-10. 